\title{
Palm kernel expellers as an alternative ingredient in growing pig diets
}

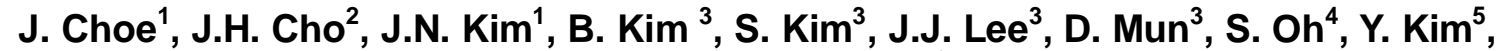 \\ H.B. $\mathrm{Kim}^{6 \#}$ \& M. Song ${ }^{3 \#}$ \\ ${ }^{1}$ Department of Beef Science, Korea National College of Agriculture and Fisheries, Jeonju 54874, South Korea \\ ${ }^{2}$ Department of Animal Science, Chungbuk National University, Cheongju 28644, South Korea \\ ${ }^{3}$ Department of Animal Science and Biotechnology, Chungnam National University, Daejeon 34134, South Korea \\ ${ }^{4}$ Department of Functional Food and Biotechnology, Jeonju University, Jeonju 55069, South Korea \\ ${ }^{5}$ Department of Animal Science and Institute of Milk Genomics, Chonbuk National University, Jeonju 54896, \\ South Korea \\ ${ }^{6}$ Department of Animal Resource Science, Dankook University, Cheonan 31116, South Korea
}

(Received 9 April 2018; Accepted 8 November 2018; First published online 21 January 2019)

\author{
Copyright resides with the authors in terms of the Creative Commons Attribution 4.0 South African Licence. \\ See: http://creativecommons.org/licenses/by/4.0/za \\ Condition of use: The user may copy, distribute, transmit and adapt the work, but must recognise the authors and the South \\ African Journal of Animal Science.
}

\begin{abstract}
This study evaluated the effects of palm kernel expellers in growing diets on growth performance, nutrient digestibility, and carcass and meat quality characteristics of growing-finishing pigs. A total of 88 growing pigs were randomly assigned to two dietary treatment groups. The control diet (CON) was a typical growing or finishing diet based on corn-soybean meal, and the treatment diet (PKE) was formulated by replacing CON with $20 \%$ palm kernel expellers. The PKE-CON group was fed the PKE diet during the growing period (six weeks) and the CON diet during the finishing period (12 weeks). The CON-CON group was fed the CON diets during both growing and finishing periods. The PKE-CON group showed significantly depressed growth performance and lower nutrient digestibility than the CON-CON group during the growing period. However, after feeding the typical finisher diets during the finishing period, the PKE-CON group showed no difference in growth performance in comparison with the CON-CON group during both the finishing and overall experimental periods. In addition, carcass and meat quality characteristics were not significantly different between the PKE-CON and the CON-CON groups. The results of this study imply that palm kernel expellers can be an alternative ingredient in the growing diets of growing-finishing pigs if the combined feeding strategy (PKE for the growing period and CON for the finishing period) is used.
\end{abstract}

Keywords: Feed alternatives, growing pig diet, growth performance, meat quality traits, palm kernel expeller \# Co-corresponding authors: hbkim@dankook.ac.kr; mhsong@cnu.ac.kr

\section{Introduction}

Feed costs are the most important factor in the livestock industry because it comprises the largest proportion (about 60 - 70\%) in animal production costs (Lawrence et al., 2008). In general, corn and soybean meal are the main ingredients of the conventional swine diet. Due to high competition between human and animal usages, however, the price of those ingredients has dramatically increased (Lawrence et al., 2008). Thus, there is a need to find alternative feed ingredients to reduce costs (Son et al., 2013).

Palm kernel expellers (PKE) is an example of such an alternative feed ingredient. PKE is a co-product of oil palm fruits (Elaeis guineensis) after mechanical oil extraction. PKE contains more oil than palm kernel meal (PKM), the co-product of oil palm kernel after solvent oil extraction, compared to mechanical oil extraction, which is less efficient (Sharmila et al., 2014). Other compositions (protein, crude fibre and carbohydrate) between PKE and PKM are similar (Sharmila et al., 2014). However, the production cost of PKE is lower than that of PKM (Alimon, 2004; Sharmila et al., 2014). Thus, PKE has a benefit in terms of cost in comparison with corn and soybean meal, as well as PKM. In addition, PKE can be supplied continuously at low cost because oil palm fruits are abundant in the tropical areas of the world (O'Mara et al., 1999; Sulabo et al., 2013; Sharmila et al., 2014).

It is well known that palm kernel co-products, including PKE and PKM, have mainly been used in 
ruminant diets because they have a higher fibre content and lower crude protein content than corn and soybean meal (O'Mara et al., 1999; Sharmila et al., 2014; Kim et al., 2015; 2016). Palm kernel co-products in particular have an inferior amino acids profile, including lysine and methionine which are the most important amino acids for pigs, and poor overall amino acid digestibility, compared to that of soybean meal (NRC, 2012; Sulabo et al., 2013; Son et al., 2014; Stein et al., 2015). Despite the high fibre content and poor amino acids profile, many attempts have been made to evaluate its feeding potential to sows (Kim et al., 2015), weaned pigs (Jaworski et al., 2014; Seo et al., 2015), growing pigs (Son et al., 2012; 2013; 2014; Sulabo et al., 2013), finishing pigs (Kim et al., 2001; Ao et al., 2011), or growing-finishing pigs (Rhule, 1996). However, previous studies have shown that palm kernel co-products as an alternative to corn and soybean meal do not have a definite, positive impact on growth performance and nutrient digestibility, for instance, relatively low weight gain (Rhule, 1996; Ao et al., 2011; Son et al., 2012). Specifically, palm kernel co-products in growing and finishing diets had a negative effect on carcass characteristics such as low dressing percentage and smaller loin eye area (Rhule, 1996). Moreover, there is insufficient literature on the effects of palm kernel co-products on meat quality traits.

Nevertheless, the low price of palm kernel co-products remains an attractive aspect of pig production. Thus, this study hypothesized that the combined feeding strategy (feeding pigs with the PKE diet for the growing period and a typical diet for the finishing diet) may reduce the negative effect of PKE on growth performance and carcass characteristics. Therefore, the objective of this study was to evaluate the effects of PKE in a growing diet on growth performance, nutrient digestibility, carcass characteristics, and meat quality traits of growing-finishing pigs.

\section{Materials and Methods}

The experimental protocol for this study was reviewed and approved by the Animal Care and Use Committee of Chungnam National University (Approval\# CNU-0611).

In the current study, over a period of 18 weeks, a total of 88 growing pigs [Duroc $x$ (Landrace $x$ Yorkshire); average initial BW of $22.58 \pm 1.58 \mathrm{~kg}$ ] were raised. The pigs were randomly assigned to two dietary treatments (4 pigs/replicate, 11 replicates/treatment) in a randomized complete block design. Each treatment pen had an equal number of barrows and gilts ( 2 males and 2 females) as a block. The dietary treatments were: 1) a typical grower diet (CON) based on corn and soybean meal; and 2) a PKE diet (PKE) in which CON was replaced with $20 \%$ PKE. The dietary treatments were formulated to meet or exceed the nutrient requirements of growing pigs (NRC, 2012) and were of similar composition, including metabolizable energy, crude protein, calcium, phosphorus, and amino acids (Table 1). The PKE replacement level was determined by the recommendations in previous literature (Zahari \& Alimon, 2004) and also considered the crude fat content (less than 5\%). The pigs were fed respective treatment diets during the growing period (six weeks) and then a typical finisher diet regardless of the dietary treatments during the finishing period (12 weeks). All pigs were housed in an environmentally controlled room (temperature: $20 \pm 2{ }^{\circ} \mathrm{C}$; relative humidity: $50 \sim 60 \%$ ) with a slatted plastic floor, and were allowed free access to feed and water throughout the entire experiment period.

The pig BW was weighed at the beginning and end of each period. The quantity of treatment diet provided per pen was recorded during each period and feed remains were weighed at the end of each period. Growth performance was measured by calculating the average daily gain (ADG), average daily feed intake (ADFI), and gain to feed ratio ( $G$ : $F$ ratio) of pigs (4 pigs/replicate, 11 replicates/treatment) during the growing, finishing and overall experimental periods, respectively.

The pigs were fed respective treatment diets containing $0.2 \%$ chromic oxide as an indigestible marker for the last week of growing period. Faecal samples from one barrow and one gilt in each pen, randomly selected, were collected daily by rectal palpation for the last $3 \mathrm{~d}$ after a 4-d adjustment period. The collected samples were pooled and stored at $-20^{\circ} \mathrm{C}$ until analysis. Diet samples were also collected from each batch of manufactured feed and stored at $-20^{\circ} \mathrm{C}$ until analysis.

Faecal samples were dried in a forced-air drying oven at $60^{\circ} \mathrm{C}$ and ground using a cyclone mill (Foss Tecator Sycltec 1093, Hillerød, Denmark) before analysis. Diet and faecal samples were analyzed for dry matter (DM, method 930.15) (AOAC, 2012), nitrogen (N, method 988.05) (AOAC, 2012), gross energy (GE) using a bomb calorimeter (Parr 1281 Bomb Calorimeter, Parr Instrument Co., Moline, IL, USA), and chromium content using an absorption spectrophotometer (Hitachi Z-5000 Absorption Spectrophotometer, Hitachi High-Technologies Co., Tokyo, Japan). Apparent total tract digestibility (ATTD) of DM, N and gross energy (GE) of growing pigs were calculated based on the testing procedure of Williams et al. (1962).

After 18 weeks, one barrow and one gilt were randomly selected from each pen and transported to the nearest local commercial slaughterhouse. The final BW of each pig was recorded and the pigs were treated 
according to the conventional slaughter process of scalding and singeing. The hot carcass weight was recorded and carcass yield was calculated by comparing final live body weight and hot carcass weight. After splitting, carcasses were chilled at $2{ }^{\circ} \mathrm{C}$ for $24 \mathrm{~h}$. At $24 \mathrm{~h}$ post-mortem, the backfat thickness was directly measured and fat-free lean (\%) was calculated using the equation provided by the National Pork Producer Council (NPPC, 1999). After chilling at $2{ }^{\circ} \mathrm{C}$ for $24 \mathrm{~h}$, the pork loin samples for meat quality measurements were taken between the 10th and 11th ribs from the right side of the carcass for measurement of the loin eye area, stored in the chilling box, and immediately moved to the laboratory. Lastly, meat quality characteristics were measured on the same day.

Table 1 Composition of experimental diets during growing and finishing periods (as-fed basis)

\begin{tabular}{|c|c|c|c|c|}
\hline \multirow{2}{*}{ Item } & \multirow{2}{*}{$\begin{array}{c}\text { Period } \\
\text { Treatments }^{1}\end{array}$} & \multicolumn{2}{|c|}{ Growing } & \multirow{2}{*}{$\frac{\text { Finishing }}{\text { CON }}$} \\
\hline & & CON & PKE & \\
\hline \multicolumn{5}{|l|}{ Ingredient (\%) } \\
\hline Corn & & 69.30 & 53.15 & 79.70 \\
\hline Soybean meal, $48 \%$ & & 26.00 & 22.00 & 18.00 \\
\hline Palm kernel expeller & & - & 20.00 & - \\
\hline Soybean oil & & 2.00 & 2.00 & - \\
\hline Dicalcium phosphate & & 1.00 & 1.00 & 0.80 \\
\hline Limestone & & 0.90 & 0.90 & 0.70 \\
\hline Salt & & 0.40 & 0.40 & 0.40 \\
\hline Vitamin premix ${ }^{2}$ & & 0.15 & 0.15 & 0.15 \\
\hline Mineral premix ${ }^{3}$ & & 0.15 & 0.15 & 0.15 \\
\hline L-lysine-HCl & & 0.10 & 0.25 & 0.10 \\
\hline Total & & 100 & 100 & 100 \\
\hline \multicolumn{5}{|c|}{ Calculated energy and nutrient contents } \\
\hline $\mathrm{ME}(\mathrm{Mcal} / \mathrm{kg})$ & & 3.39 & 3.32 & 3.30 \\
\hline Crude protein (\%) & & 18.20 & 18.50 & 15.00 \\
\hline Crude fat (\%) & & 2.81 & 4.43 & 3.05 \\
\hline Crude fibre (\%) & & 2.38 & 5.25 & 2.28 \\
\hline NDF (\%) & & 8.45 & 17.94 & 8.74 \\
\hline ADF (\%) & & 3.37 & 10.15 & 3.25 \\
\hline Calcium (\%) & & 0.67 & 0.72 & 0.53 \\
\hline Phosphorus (\%) & & 0.55 & 0.59 & 0.49 \\
\hline Lysine (\%) & & 1.03 & 1.06 & 0.82 \\
\hline Methionine (\%) & & 0.30 & 0.29 & 0.26 \\
\hline Threonine (\%) & & 0.68 & 0.63 & 0.56 \\
\hline Tryptophan (\%) & & 0.21 & 0.20 & 0.17 \\
\hline
\end{tabular}

${ }^{1} \mathrm{CON}=$ control diet based on corn and soybean meal; PKE = palm kernel expeller diet

${ }^{2}$ Provided per kilogram of diet: vitamin A, $10000 \mathrm{IU}$; vitamin $\mathrm{D}_{3}, 2000 \mathrm{IU}$; vitamin E, $48 \mathrm{IU}$; vitamin $\mathrm{K}_{3}, 1.5 \mathrm{mg}$; riboflavin, $6 \mathrm{mg}$; niacin, $40 \mathrm{mg}$; D-pantothenic acid, $17 \mathrm{mg}$; biotin, $0.2 \mathrm{mg}$; folic acid, $2 \mathrm{mg}$; choline, $166 \mathrm{mg}$; vitamin $\mathrm{B}_{6}, 2 \mathrm{mg}$; and vitamin $B_{12}, 28 \mu \mathrm{g}$

${ }^{3}$ Provided per kilogram of diet: Fe, $90 \mathrm{mg}$ from iron sulfate; $\mathrm{Cu}, 15 \mathrm{mg}$ from copper sulfate; $\mathrm{Zn}, 50 \mathrm{mg}$ from zinc oxide; $\mathrm{Mn}, 54 \mathrm{mg}$ from manganese oxide; I, $0.99 \mathrm{mg}$ from potassium iodide; Se, $0.25 \mathrm{mg}$ from sodium selenite $\mathrm{ME}$, metabolizable energy; NDF, neutral detergent fibre; ADF, acid detergent fibre

In order to measure the water-holding capacity (WHC), a $0.3 \mathrm{~g}$ sample was pressed at $3000 \times g$ for 3 $\min$ at $26^{\circ} \mathrm{C}$ on a $125-\mathrm{mm}$-diameter piece of filter paper. The loin eye area of the pressed sample and the expressed moisture were delineated and then determined using a digitizing area-line sensor (MT-10S, M.T. 
Precision Co. Ltd., Tokyo, Japan). The ratio of water to meat area was then calculated, giving a measure of WHC (a smaller ratio indicates increased WHC) (Kauffman et al., 1986). At the same time, duplicate pH values of each sample were directly measured using a pH meter, which was calibrated using two standard solutions ( $\mathrm{pH} 4$ and 7) with automatic temperature compensation (Fisher Scientific, Pittsburgh, PA).

Subjective meat colour, marbling and firmness scores were evaluated by 20 trained panels according to NPPC (1991) standards. The panels were trained over a period of four weeks to assess meat samples for color, marbling and firmness until no significant differences were observed on the same sample between the trained panels. After $30 \mathrm{~min}$ air exposure at $4{ }^{\circ} \mathrm{C}$ for bloom, subjective pork loin colour scores on a scale from 1 to 5 ( 1 = pale grey, $5=$ dark purplish red), marbling scores on a scale from 1 to 5 ( $1=$ none to slight, $5=$ moderate to abundant and firmness scores on a scale from 1 to 5 ( 1 = very soft and very watery, $5=$ very firm and dry) were determined. After subjective evaluation, meat colour (Commission Internationale de l'Eclairage lightness, redness, and yellowness) was immediately measured using a chromameter (Model CR210 Chromameter, Konica Minolta Sensing Inc., Osaka, Japan). The CR-210 uses a pulsed xenon lamp as a light source in the measuring head. The calibration was made by using the white calibration plate supplied by the manufacturer. The illuminant used was $\mathrm{C}$, and the standard observer position was $2^{\circ}$. The optical fibre cable collected only the light reflected perpendicular to the specimen surface for colour analysis. Drip loss was measured using approximately $2 \mathrm{~g}$ of meat sample according to the plastic bag method described by Honikel (1998). Cooking loss was determined as described previously by Sullivan et al. (2007).

Data were firstly tested for normality by using the NORMAL test option of the PROC UNIVARIATE and were then analyzed using the PROC GLM of SAS (SAS Inst. Inc., Cary, NC, USA) in a randomized complete block design. The experimental unit was the pen and the block was the sex. The statistical model for growth performance, nutrient digestibility, carcass characteristics, and meat quality characteristics included the effect of dietary treatments as the fixed effect and sex as the random effect. Results were expressed as the least square means \pm standard deviation. Statistical significance and tendency were considered at $P<0.05$ and $0.05 \leq P<0.10$, respectively.

\section{Results and Discussion}

The pigs fed the PKE diet during the growing period showed significantly lower $(P<0.05)$ growth performance including feed intake, ADG, ADFI and G:F ratio, compared to those fed the CON diet (Table 2).

In the result of ATTD, all parameters (DM, N, and GE) in the PKE group were significantly lower ( $P$ $<0.05$ ) than those in the CON group (Table 3). As expected, these results are consistent with results of previous studies (Kim et al., 2001; Sulabo et al., 2013; Son et al., 2014). As regards non-ruminants, PKE is not a suitable source of energy (Seo et al., 2015) due to its lack of available energy. Generally, PKE has a lower energy density, poor amino acid profile and higher fibre content for non-ruminants, compared to conventional feed ingredients (Son et al., 2012; Sulabo et al., 2013; Seo et al., 2015). This may reduce the nutrient digestibility and metabolized energy of PKE (Noblet \& Le Goff, 2001; Seo et al., 2015). In addition, the relatively low palatability of PKE and apparently enhanced satiety of the pigs could be due to its high fibre content, compared to conventional ingredients (McDonald et al., 2011). This could account for the lower feed intake and ADFI of the pigs in the PKE, and the decrease in ATTD of DM, N and GE, resulting in decreased ADG, G : F ratio, and final BW at the end of the growing period, compared to pigs in the CON. Another possible reason of the decreased feed intake in the PKE treatment group is the fat content of the diet. The fat level in the PKE diet was more than $3 \%$ in this study. It has been reported that a fat content of more than 3\% in swine diets may decrease feed intake slightly (Azain, 2000). The higher fat content of the PKE diet than the CON diet in this study may be derived from the high residual oil content of PKE, which may result in reduced feed intake and ADFI of the PKE group.

The combined feeding strategy was applied in the present study to reduce a negative effect of PKE on growth performance. As the result of feeding the typical finisher diets during the finishing period, the growth performance of the PKE-CON was not significantly different to that of the CON-CON during both the finishing and overall experimental periods (Table 2). This implies that there may be no carry-over effect of the PKE diets when the typical diets are applied. Moreover, the results of feed intake may indicate indirectly that the PKE diet has a relatively lower palatability and enhanced satiety in comparison with conventional ingredients. Contrary to the growing period, when the diets were changed from the PKE to the CON, the PKE-CON showed no significant difference on feed intake and ADFI to the CON-CON during both the finishing and overall experimental periods. 
Table 2 Growth performance of growing-finishing pigs fed dietary treatments during each period ${ }^{1}$

\begin{tabular}{lccc}
\hline \multirow{2}{*}{ Item } & \multicolumn{2}{c}{ Treatments $^{2}$} & P-value \\
\cline { 2 - 3 } Growing period (0 - 42 d) & CON-CON & PKE-CON & 0.131 \\
Body weight at 0 d & $22.1 \pm 1.60$ & $23.1 \pm 1.44$ & $<0.05$ \\
Body weight at 42 d & $48.8 \pm 2.80$ & $45.6 \pm 2.38$ & $<0.05$ \\
Feed intake (kg) & $70.3 \pm 1.61$ & $66.2 \pm 1.61$ & $<0.05$ \\
ADG (g/d) & $637 \pm 47.6$ & $536 \pm 53.5$ & $<0.05$ \\
ADFI (g/d) & $1674 \pm 38.4$ & $1577 \pm 38.4$ & $<0.05$ \\
G : F ratio (g/g) & $0.38 \pm 0.02$ & $0.34 \pm 0.04$ & 0.169 \\
Finishing period (43 - 126 d) & & & 0.923 \\
Body weight at 126 d & $105.7 \pm 5.73$ & $102.3 \pm 5.19$ & 0.972 \\
Feed intake (kg) & $194 \pm 15.1$ & $195 \pm 25.9$ & 0.923 \\
ADG (g/d) & $677 \pm 82.6$ & $675 \pm 72.1$ & 0.445 \\
ADFI (g/d) & $2309 \pm 180.2$ & $2319 \pm 308.2$ & 0.089 \\
G : F ratio (g/g) & $0.29 \pm 0.06$ & $0.29 \pm 0.06$ & 0.724 \\
Overall period (0 - 126 d) & & & 0.507 \\
ADG (g/d) & $663 \pm 48.31$ & $629 \pm 42.26$ & $2072 \pm 197.2$ \\
ADFI (g/d) & $2097 \pm 128.0$ & $0.31 \pm 0.04$ & \\
G : F ratio (g/g) & $0.32 \pm 0.04$ & &
\end{tabular}

The normality was tested by using the NORMAL test option of the PROC UNIVARIATE and the difference between treatments was determined by using PROC GLM of SAS in randomized complete block design

${ }^{1}$ Values are presented as the least squares mean with standard deviation of 11 replicates (4 pigs/replicate). The growing, finishing, and growing-finishing periods were six, 12, and 18 weeks, respectively

${ }^{2} \mathrm{CON}-\mathrm{CON}=$ control diet based on corn and soybean meal for both growing and finishing periods; PKE-CON = palm kernel expeller diet for growing period and control diet based on corn and soybean meal for finishing period $A D G=$ average daily gain, $A D F I=$ average daily feed intake, $G: F$ ratio $=$ ratio between $A D G$ and $A D F I$

Table 3 Apparent total tract digestibility of growing pigs fed dietary treatments ${ }^{1}$

\begin{tabular}{lccc}
\hline \multirow{2}{*}{ Item } & \multicolumn{2}{c}{ Treatments $^{2}$} & \multirow{2}{*}{ P-value } \\
\cline { 2 - 3 } & CON & PKE & $<0.05$ \\
Dry matter (\%) & $80.7 \pm 1.60$ & $77.0 \pm 3.47$ & $<0.05$ \\
Nitrogen (\%) & $75.6 \pm 2.30$ & $71.6 \pm 4.38$ & $<0.05$ \\
Energy (\%) & $80.9 \pm 1.52$ & $76.5 \pm 3.23$ & \\
\hline
\end{tabular}

The normality was tested by using the NORMAL test option of the PROC UNIVARIATE, and the difference between treatments was determined by using PROC GLM of SAS in randomized complete block design

${ }^{1}$ Values are presented as the least squares mean with standard deviation of 11 replicates (2 pigs/replicate). The growing period was six weeks

${ }^{2} \mathrm{CON}=$ control diet based on corn and soybean meal during growing period; PKE = palm kernel expeller diet during growing period

There is insufficient literature to elucidate the effect of a PKE supplementary diet during the growing period on carcass and meat quality characteristics of finishing pigs. Therefore, this study investigated the carcass and meat quality characteristics of PKE treated pigs. No differences in carcass characteristics between the CON-CON and the PKE-CON (Table 4) were found, except for hot carcass weight. Hot carcass weight of the PKE-CON was significantly lower than that of the CON-CON. Results of previous studies 
showed that the use of palm kernel co-products in growing-finishing diets did not influence dressing percentage, back-fat thickness and loin eye area (Fetuga et al., 1977a, 1977b; Ao et al., 2011), which are similar to the results of the present study. However, some studies showed that swine diets supplemented with $40 \%$ palm kernel co-products significantly decreased dressing percentage (Rhule, 1996, 1998). Another study reported an increase in the leanness of the carcass commensurate with an increase in palm kernel coproduct in the diet (Fetuga et al., 1977a; 1977b). Previous studies demonstrated that fat deposition is inhibited because feeding palm kernel co-product restricts digestible energy intake (Fetuga et al., 1977a; 1977b). As mentioned earlier, PKE has a high fibre content which cannot be digested by non-ruminant

Table 4 Carcass and meat quality characteristics of growing-finishing pigs fed dietary treatments ${ }^{1}$

\begin{tabular}{|c|c|c|c|}
\hline \multirow{2}{*}{ Item } & \multicolumn{2}{|c|}{ Treatments $^{2}$} & \multirow{2}{*}{$P$-value } \\
\hline & CON-CON & PKE-CON & \\
\hline \multicolumn{4}{|l|}{ Carcass characteristics } \\
\hline Final body weight (kg) & $107.3 \pm 5.73$ & $103.9 \pm 5.19$ & 0.235 \\
\hline Hot carcass weight $(\mathrm{kg})$ & $85.3 \pm 2.10$ & $82.2 \pm 2.92$ & $<0.05$ \\
\hline Carcass yield (\%) & $79.5 \pm 4.49$ & $79.1 \pm 5.34$ & 0.875 \\
\hline Loin eye area $\left(\mathrm{cm}^{2}\right)$ & $47.7 \pm 1.19$ & $47.4 \pm 1.34$ & 0.601 \\
\hline Backfat thickness (mm) & $20.0 \pm 2.24$ & $18.6 \pm 2.29$ & 0.173 \\
\hline Fat free lean $(\%)^{3}$ & $59.2 \pm 0.93$ & $58.9 \pm 1.12$ & 0.533 \\
\hline \multicolumn{4}{|l|}{ Meat quality characteristics } \\
\hline $\mathrm{pH}_{24 \mathrm{~h}^{4}}$ & $5.67 \pm 0.07$ & $5.61 \pm 0.10$ & 0.127 \\
\hline Water holding capacity (\%) & $51.4 \pm 2.30$ & $50.4 \pm 2.64$ & 0.365 \\
\hline \multicolumn{4}{|l|}{ Drip loss (\%) } \\
\hline d 0 to $1(\%)$ & $6.31 \pm 0.53$ & $6.45 \pm 0.78$ & 0.634 \\
\hline d 0 to $3(\%)$ & $11.39 \pm 1.00$ & $11.59 \pm 0.92$ & 0.634 \\
\hline d 0 to $5(\%)$ & $17.09 \pm 0.90$ & $17.26 \pm 0.70$ & 0.645 \\
\hline d 0 to $7(\%)$ & $22.75 \pm 0.75$ & $22.77 \pm 0.90$ & 0.954 \\
\hline Cooking loss (\%) & $42.6 \pm 1.93$ & $43.8 \pm 3.25$ & 0.319 \\
\hline \multicolumn{4}{|l|}{ Meat colour } \\
\hline Lightness & $59.3 \pm 0.77$ & $59.3 \pm 0.96$ & 0.985 \\
\hline Redness & $15.06 \pm 0.43$ & $14.96 \pm 0.45$ & 0.599 \\
\hline Yellowness & $12.30 \pm 0.23$ & $12.49 \pm 0.18$ & $<0.05$ \\
\hline \multicolumn{4}{|l|}{ Subjective evaluation score ${ }^{5}$} \\
\hline Colour & $1.60 \pm 0.10$ & $1.53 \pm 0.10$ & 0.110 \\
\hline Marbling & $1.56 \pm 0.09$ & $1.52 \pm 0.08$ & 0.240 \\
\hline Firmness & $1.56 \pm 0.18$ & $1.52 \pm 0.11$ & 0.514 \\
\hline
\end{tabular}

The normality was tested by using the NORMAL test option of the PROC UNIVARIATE and the difference between treatments was determined by using PROC GLM of SAS in randomized complete block design.

${ }^{1}$ Values are presented as the least squares mean with standard deviation of 11 replicates (2 pigs/replicate). The growing-finishing period was 18 weeks.

${ }^{2} \mathrm{CON}-\mathrm{CON}=$ control diet based on corn and soybean meal for both growing and finishing periods; PKE-CON = palm kernel expeller diet for growing period and control diet based on corn and soybean meal for finishing period.

${ }^{3}$ Fat-free lean (\%) was calculated using NPPC (1999) equation.

${ }_{5}^{4}$ Muscle $\mathrm{pH}$ measured at postmortem $24 \mathrm{~h}$.

${ }^{5}$ Subjective pork loin colour scores on a scale from 1 to 5 ( $1=$ pale grey, to $5=$ dark purplish red), pork loin marbling scores on a scale from 1 to 5 ( $1=$ devoid to practically devoid, to $5=$ moderately abundant or greater), and pork loin firmness scores on a scale from 1 to 5 ( $1=$ very soft and very watery, to $5=$ very firm and dry) were determined 
animals; this constitutes a significant restriction as regards the intake energy from the PKE-supplemented diet for pigs. However, this could not be confirmed in the current study due to the limited sample size. A larger sample size might elicit a more detailed energy pathway and partitioning when pigs ingest PKE diets.

No significant differences were found in meat quality characteristics between the CON-CON and PKECON groups (Table 4), except yellowness in meat colour. The PKE-CON showed slightly higher yellowness than the CON-CON. It is generally accepted that meat colour is the main factor that influences consumer purchase decisions (Choe et al., 2016). Although yellowness was different between treatment groups, there were no colour differences in the lightness and redness of meat (Mancini \& Hunt, 2005). In addition, the panels could not distinguish the colour differences between treatments when assessed subjectively. Although there were limitations due to sample size and assessments by the trained panels based on the NPPC standard (1991), the subjective colour was sufficiently acceptable. Another important quality factor is WHC, which is related to both visual traits and eating satisfaction affecting consumer purchase decision and intention to repurchase (Choe et al., 2016). In this study, WHC was measured objectively by drip loss, cooking loss and centrifuge methods, and there were no differences in WHC parameters between treatment groups, which can be accounted for by postmortem muscle $\mathrm{pH}$. WHC is closely related to postmortem muscle $\mathrm{pH}$ (Ryu \& Kim, 2005). There were no differences on both muscle pH at postmortem $24 \mathrm{~h}$ and WHC measurements between the PKE-CON and the CON-CON.

\section{Conclusion}

Based on the results of this study, feeding typical diets replaced by $20 \%$ PKE during the growth period may depress growth. However, when the pigs were fed the typical finisher diets during the finishing period, there was no deteriorating influence on growth performance, carcass and meat quality of growing-finishing pigs. It could be concluded that PKE can be an alternative in growing diets for growing-finishing pigs if the combined feeding strategy is used (PKE for the growing period and CON for the finishing period).

\section{Acknowledgment}

This research was supported by a grant from the Next-Generation BioGreen 21 Program (PJ01322302), Rural Development Administration, Republic of Korea.

\section{Authors' Contributions}

$\mathrm{JC}, \mathrm{JHC}, \mathrm{JNK}$, and BK contributed equally to this work as the first authors. JC, JHC, JNK, BK, HBK, and MS designed this experiment. JC, JHC, JNK, BK, SK, JJL, DM, SO, YK, HBK, and MS performed the animal experiment, measured and acquired the data, and evaluated the carcass characteristics. JC, JHC, JNK, BK, SK, JJL, DM, SO, YK, $\mathrm{HBK}$, and MS analyzed the data and wrote the manuscript. HBK and MS supervised all processes through performing the experiment to writing the manuscript. All authors read and approved the final manuscript.

\section{Conflict of interest declaration}

The authors have declared that there are no competing interests.

\section{References}

Alimon, A.R., 2004. The nutritive value of palm kernel cake for animal feed. Palm Oil Dev. 40, 12-16.

Ao, X., Zhou, T.X., Meng, Q.W., Lee, J.H., Jang, H.D., Cho, J.H. \& Kim, I.H., 2011. Effects of a carbohydrase cocktail supplementation on the growth performance, nutrient digestibility, blood profiles and meat quality in finishing pigs fed palm kernel meal. Livest. Sci. 137, 238-243.

AOAC, 2012. Official methods of analysis of AOAC International. Association of Official Analytical Chemists, Gaithersburg, MD, USA.

Azain, M.J., 2000. Fat in swine nutrition. In: Swine Nutrition. Lewis, A.J. \& Southern, L.L. (eds). CRC Press, Boca Raton, Florida, USA. pp. 95-105.

Choe, J.H., Choi, M.H., Rhee, M.S. \& Kim, B.C., 2016. Estimation of sensory pork loin tenderness using Warner-Bratzler shear force and texture profile analysis measurements. Asian-Austral. J. Anim. Sci. 29, 1029-1036.

Fetuga, B.L., Babatunde, G.M. \& Oyenuga, V.A., 1977a. The value of palm kernel meal in finishing diets for pigs: 1. The effect of varying the proportion of protein contribution from blood meal and palm kernel meal on the performance and carcass quality of finishing pigs. J. Agric. Sci. 88, 655-661.

Fetuga, B.L., Babatunde, G.M. \& Oyenuga, V.A., 1977b. The value of palm kernel meal in finishing diets for pigs: 2 . The effect of the addition of cane molasses on the utilization of high level palm kernel meal diets. J. Agric. Sci. 88, 663669.

Honikel, K.O., 1998. Reference methods for the assessment of physical characteristics of meat. Meat Sci. 49, 447-457.

Jaworski, N.W., Shoulders, J., González-Vega, J.C. \& Stein, H.H., 2014. Effects of using copra meal, palm kernel expellers, or palm kernel meal in diets for weanling pigs. Prof. Anim. Sci. 30, 243-251.

Kauffman, R.G., Eikelenboom, G., Van der Wal, P.G., Engel, B. \& Zaar, M., 1986. A comparison of methods to estimate water-holding capacity in post-rigor porcine muscle. Meat Sci. 18, 307-322.

Kim, B.G., Lee, J.H., Jung, H.J., Han, Y.K., Park, K.M. \& Han, I.K., 2001. Effect of partial replacement of soybean meal with palm kernel meal and copra meal on growth performance, nutrient digestibility and carcass characteristics of 
finishing pigs. Asian-Austral. J. Anim. Sci. 14, 821-830.

Kim, J., Seo, J., Kim, W., Yun, H.M., Kim, S.C., Jang, Y., Jang, K., Kim, K., Kim, B., Park, S., Park, I., Kim, M.K., Seo, K.S., Kim, H.B., Kim, I.H., Seo, S. \& Song, M., 2015. Effects of palm kernel expellers on productive performance, nutrient digestibility, and white blood cells of lactating sows. Asian-Austral. J. Anim. Sci. 28, 1150-1154.

Kim, S., Kim, B., Kim, Y., Jung, S., Kim, Y., Park, J., Song, M. \& Oh, S., 2016. Value of palm kernel co-products in swine diets. Korean J. Agric. Sci. 43, 761-768.

Lawrence, J.D., Mintert, J., Anderson, J.D. \& Anderson, D.P., 2008. Feed grains and livestock: Impacts on meat supplies and prices. Choices: The mag. Food, Farm, Resour. Iss. 23, 11-15.

Mancini, R.A. \& Hunt, M.C., 2005. Current research in meat color. Meat Sci. 71, 100-121.

McDonald, P., Edwards, R.A., Greenhalgh, J.F.D., Morgan, C.A., Sinclair, L.A. \& Wilkinson, R.G., 2011. Animal Nutrition. Pearson Education Limited, Harlow, UK.

Noblet, J. \& Le Goff, G., 2001. Effect of dietary fibre on the energy value of feeds for pigs. Anim. Feed Sci. Technol. 90, 35-52.

NPPC, 1991. Procedures to Evaluate Market Hogs. National Pork Producers Council, Des Moines, IA, USA.

NPPC, 1999. Pork quality standards. National Pork Producers Council, Des Moines, IA, USA.

NRC, 2012. Nutrient requirements of swine. National Academies Press, Washington DC, USA.

O'Mara, F.P., Mulligan, F.J., Cronin, E.J., Rath, M. \& Caffrey, P.J., 1999. The nutritive value of palm kernel meal measured in vivo and using rumen fluid and enzymatic techniques. Livest. Prod. Sci. 60, 305-316.

Rhule, S.W.A., 1996. Growth rate and carcass characteristics of pigs fed on diets containing palm kernel cake. Anim. Feed Sci. Technol. 61, 167-172.

Rhule, S.W.A., 1998. The influence of type of palm kernel cake on the growth rate and carcass characteristics of pigs. Ghana J. Agric. Sci. 31, 181-186.

Ryu, Y.C. \& Kim, B.C., 2005. The relationship between muscle fibre characteristics, postmortem metabolic rate, and meat quality of pig longissimus dorsi muscle. Meat Sci. 71, 351-357.

Seo, J., Kim, W., Kim, J., Kim, J.K., Kim, S.C., Jang, Y., Jang, K., Kim, K., Kim, B., Park, S., Park, I., Kim, M.K., Seo, K.S., Kim, H.B., Kim, I.H., Seo, S. \& Song, M., 2015. Effects of palm kernel expellers on growth performance, nutrient digestibility, and blood profiles of weaned pigs. Asian-Austral. J. Anim. Sci. 28, 987-92.

Sharmila, A., Alimon, A.R., Azhar, K., Noor, H.M. \& Samsudin, A.A., 2014. Improving nutritional values of palm kernel cake (PKC) as poultry feeds: a review. Malays. Soc. Anim. Prod. 17, 1-18.

Son, A.R., Ji, S.Y. \& Kim, B.G., 2012. Digestible and metabolizable energy concentrations in copra meal, palm kernel meal, and cassava root fed to growing pigs. J. Anim. Sci. 90, 140-142.

Son, A.R., Shin, S.Y. \& Kim, B.G., 2013. Standardized total tract digestibility of phosphorus in copra expellers, palm kernel expellers, and cassava root fed to growing pigs. Asian-Austral. J. Anim. Sci. 26, 1609-1613.

Son, A.R., Hyun, Y., Htoo, J.K. \& Kim, B.G., 2014. Amino acid digestibility in copra expellers and palm kernel expellers by growing pigs. Anim. Feed Sci. Technol. 187, 91-97.

Stein, H.H., Casas, G.A., Abelilla, J.J., Liu, Y. \& Sulabo, R.C., 2015. Nutritional value of high fibre co-products from the copra, palm kernel, and rice industries in diets fed to pigs. J. Anim. Sci. Biotech. 6, 56

Sulabo, R.C., Ju, W.S. \& Stein, H.H., 2013. Amino acid digestibility and concentration of digestible and metabolizable energy in copra meal, palm kernel expellers, and palm kernel meal fed to growing pigs. J. Anim. Sci. 91, 13911399.

Sullivan, Z.M., Honeyman, M.S., Gibson, L.R. \& Prusa, K.J., 2007. Effects of triticale-based diets on finishing pig performance and pork quality in deep-bedded hoop barns. Meat Sci. 76, 428-437.

Williams, C.H., David, D.J. \& lismaa, O., 1962. The determination of chromic oxide in faeces samples by atomic absorption spectrophotometry. J. Agric. Sci. 59, 381-385.

Zahari, M.W. \& Alimon, A.R., 2004. Use of palm kernel cake and oil palm by-products in compound feed. Palm Oil Dev. $40,5-9$. 